\title{
Tarımsal ve Endüstriyel Atıklar Üzerinde Kültürü Yapılan Pleurotus Taksonlarının Yă̆ Asidi Düzeylerinin Tespit Edilmesi
}

\author{
Volkan KORKMAZ ${ }^{* 1}$, Sevda KIRBAĞ ${ }^{1}$ \\ ${ }^{1}$ Fırat Üniversitesi, Fen Fakültesi Biyoloji Bölümü, Elazı̆̆
}

\begin{abstract}
Özet
Bu çalışmada, yonca sapı (YS), ceviz kabuğu atıkları (CK), şeker pancarı posası (ȘP) gibi farklı kompost ortamlarında yetiştirilen Pleurotus ostreatus (Jacq. ex. Fr) Kum. var. salignus, Pleurotus sajor-caju (FR). Singer, Pleurotus florida Fovose'nin yağ asidi kompozisyonları belirlenmiştir. Analizler gaz kromatografi cihazı ile yapılmıştır. Yağ asidi analizlerinde; linoleik asit, palmitik asit, pentadekonoik asit, stearik asit ağırlıklı olarak bulunmuştur. Türlerin en fazla palmitik asit (\%19.7-33.06), linoleik asit (\%36.69-78.89), dokosadienoik asit (\%9.78-28.80) içerdiği tespit edilmiştir. Diğer yandan laurik asit, linolenik asit, eikosadienoik asit, eikosatrieonik asit, dokosatetraenoik asit gibi yağ asitlerinin de varlığı tespit edilmiştir. Sonuç olarak; çalışılan üç takson arasında Pleurotus florida Fovose'nin daha zengin yağ asidi içeriğine sahip olduğu bulunmuştur.
\end{abstract}

Anahtar Kelimeler: Yağ asitleri, Pleurotus ostreatus. var. salignus, P. sajor-caju, P. florida

\section{The Determination of Fatty Acid Levels Pleurotus Taxa which Cultured on Agricultural And Industrial Wastes}

\begin{abstract}
In this study, fatty acid compositions of Pleurotus ostreatus (Jacq. ex. Fr) Kum.var. salignus, Pleurotus sajorcaju (FR). Singer, Pleurotus florida Fovose grown on different compost mediums such as clover stalk (CS), walnut husk waste (WH), sugar beet pulp (SP) were determined. Analysis was performed by high performance gas chromatography. According to the fatty acid analysis results, linoleic acid, palmitic acid, pentadeconoic acid, stearic acid was found predominantly. Present results showed that the studied three species have high palmitic acid (19.7-33.06\%), linoleic acid (36.69-78.89\%) and docosadyenoic acid (9.78-28.80\%). On the other hand the presence of lauric acid, linolenic acid, eicosadienoic acid, eicosatrieonic acid, docosatetraenoic acid were determined. As a result; it was found that Pleurotus florida Fovose has rich fatty acid content among the studied taxa.
\end{abstract}

Keywords: Fatty acids, Pleurotus ostreatus. var. salignus, P. sajor-caju, P. florida

\section{Giriş}

Yenilen mantarlar; tatları, aroması, besin değerleri ve tıbbi özellikleri açısından oldukça önemlidirler $[1,2]$. İnsan beslenmesinde önemli bir yere sahip olan mantarlar düşük oranda kaloriye, yağ ve yağ asitlerine sahipken proteinler, vitaminler ve mineraller açısından zengindirler [3, 4].

Pleurotus spp.'nin tüm dünyada en fazla üretilen mantar türleri içerisinde, Agaricus spp. ve $L$. edodes'ten sonra 3. sırada yer aldığ 1 ve üretim miktarının ise, yıllık bir milyon tondan daha fazla olduğu belirtilmiştir. Pleurotus cinsi mantarların şapka yapıları; midye kabuğu ve spatul benzeri, sap yapılarının ise eksantrik veya lateral olmalarından dolayı "istiridye mantarları (oyster mushroom)" olarak adlandırılmaktadırlar [5].

\footnotetext{
*Sorumlu Yazar:vkorkmaz23@gmail.com

Yüksek Lisans tezinin bir kısmını oluşturmaktadır
} 
Pleurotus spp., kültürü yapılan diğer mantar türleriyle karşılaştırıldığında; değiş̧ik agroklimatik koşullara [6], gelişmeleri için az bir süreye ve bir kaç çevresel faktöre gereksinim duydukları, bazidiokarplarının hastalık ve pestisitlere karşı daha dirençli olduğu, bunların sonucu olarak da maliyeti daha düşük ve daha basit bir şekilde kültürlerinin yapıldığı belirtilmiştir $[7,8,9]$. Ayrıca Pleurotus türlerinin de diğer mantar türlerine göre daha zengin besin içeriğine sahip oldukları belirlenmiştir $[4,10,11]$.

Pleurotus'un da bulunduğu yenilebilir mantarlar yüksek lif, protein, mikroelement içeriklerinden ve düşük yağ yapılarından dolayı arterosklerozun engellenmesinde önemli rol oynarlar. Taze mantarlar, \% 3-21 oranında karbohidrat, \% 3-35 oranında lif içerirler ve düşük kaloridirler. Aynı zamanda mantarlar mükemmel mineral ve vitamin kaynağıdırlar [12].

Bu çalışmada; Elazığ ilinde bol bulunan yonca sapı, ceviz kabukları ve şeker pancarı posası gibi tarımsal ve endüstriyel atıkların, $P$. ostreatus, $P$. sajor-caju ve $P$. florida'nın yağ asidi değerleri üzerine olan etkileri araştırılmıştır.

\section{Materyal ve Metot}

\section{1. Çalışmalarda Kullanılan Mantar Örnekleri}

$\mathrm{Bu}$ çalışmada kullanılan mantar örnekleri önceki kültür çalışmalarından elde edilmiştir. Kompost olarak; Buğday Sap1 (B), Buğday Sap1 (B) +Şeker pancarı küspesi (Ş) 1:1, Buğday Sapı (B) + Ceviz kabuğu (C) 1:1 kullanılmıştır [13].

\subsection{Yağ Asidi İçeriklerinin Belirlenmesi}

Mantarlardaki yağların izolasyonu 3/2 (v/v) hekzan/izopropil alkol karışımıyla etkileştirilirken, yağ asidi metil esterleri \% 2'lik metanolik H2SO4 karışımıyla (2 ml asit $+98 \mathrm{ml}$ metanol) etkileştirildi ve sonra hekzan ile ekstrakte edildi. Analizler Shimadzu GC 17. marka gaz kromatografi cihazi ile yapılmıştır $[14,15]$.

\section{Bulgular}

Mantar örneklerinde; Laurik Asit, Pentadekonoik asit, Palmitik asit, Palmitoleik asit, Stearik asit, Oleik asit, Linoleik asit, Linolenik asit, Eikosadienoik asit, Eikosatrienoik asit, Dokosanoik asit, Dokosadienoik asit, Dokosatetraenoik belirlenmiştir.

Pleurotus spp.'de, kullanılan materyale bağlı olarak; Laurik Asit \%0.0-1.349, Pentadekonoik asit \%0.0-1.447, Palmitik asit \%0.0-33.064, Palmitoleik asit \%0.0-1.443, Stearik asit \%0.0-15.800, Oleik asit \%0.0-53.499, Linoleik asit \%0.0-78.893, Linolenik asit \%0.0-2.780, Eikosadienoik asit \%0.0-1.980, Eikosatrienoik asit \%0.0-2.768, Dokosanoik asit \%0.0-1.601, Dokosadienoik asit \%0.028.707 ve Dokosatetraenoik asit \%0.0-2.293 olarak tespit edilmiştir (Tablo 1).

P. ostreatus'da YS ortamında; Palmitik asit \%26.671, Stearik asit \%15.800, Linoleik asit \%41.984, Dokosadienoik asit \%15.543 olarak değiştiği saptanmıştır. YS-CK ortamında; Palmitik asit $\% 22.637$, Stearik asit \%14.077, Oleik asit \%53.499, Dokosadienoik asit \%9.785 olarak tespit edilmiştir. YS-ŞP ortamında; Palmitik asit \%33.064, Oleik asit \%18.829, Linoleik asit \%36.694, Dokosadienoik asit \%11.411 olarak belirlenmiştir (Tablo 1).

P. florida'nın YS ortamında elde edilen mantar örneklerinde; Laurik Asit \%1.349, Pentadekonoik asit \%1.447, Palmitik asit \%19.781, Palmitoleik asit \%1.443, Stearik asit \%6.741, Oleik asit \%20.165, Linoleik asit \%36.958, Linolenik asit \%2.259, Eikosadienoik asit \%1.980, Eikosatrienoik asit \%2.768, Dokosanoik asit \%1.601, Dokosadienoik asit \%0.0 ve Dokosatetraenoik 
asit ise \%2.293 olarak belirlenmiştir. YS-CK ortamında; Palmitik asit \%18.394, Oleik asit \%30.834, Linoleik asit \%39.928 ve Dokosadienoik asit \%10.842 olarak saptanmıştır. YS-ŞP ortamlarındaki mantar örneklerin de ise Palmitik asit \%19.156, Stearik asit \%6.087, Oleik asit \%22.335, Linoleik asit \%47.200, Linolenik asit \%2.780 ve Eikosatrienoik asit \%2.439 tespit edilmiştir (Tablo 1).

P. sajor-caju'nun YS ortamında; Palmitik asit \%31.124, Stearik asit \%10.610, Linoleik asit \%38.908, Dokosadienoik asit \%19.356 olarak tespit edilmiştir. YS-CK ortamında; Linoleik asit $\% 71.292$ ve Dokosadienoik asit \%28.707, YS-ŞP ortamında ise Palmitik asit \%21.106 ve Linoleik asit \%78.893 olarak belirlenmiştir (Tablo 1).

\section{Tartışma}

Bir çalışmada $P$. ostreatus şapka yapısında; palmitik asit \%14.0, Stearik asit \%3.0, Oleik asit $\% 18.0$ ve Linoleik asit \%65.0. Misellerinde ise, palmitik asit \%35.0, Stearik asit \%5.5, Oleik asit \%22.0 ve Linoleik asit \%37.5 olarak değişkenlik gösterdiği belirtilmiştir [16].

Farklı oranlardaki lokal atıklarda kültürü yapılan $P$. ostreatus'un yağ asidi $\left(\mathrm{C}_{14: 0}, \mathrm{C}_{15: 0}, \mathrm{C}_{16: 0}\right.$, $\mathrm{C}_{16: 1}, \mathrm{C}_{17: 0}, \mathrm{C}_{18: 0}, \mathrm{C}_{18: 1}, \mathrm{C}_{18: 2}, \mathrm{C}_{20: 0}$ ) kompozisyonu bakımından ise değişken olduğu ve doymamış yağ asitleri bakımından zengin iyi bir diyet besin kaynağı olduğu belirtilmiştir [17].

S. commune'de; Palmitik asit \%20.8, Stearik asit \%2.5, Arakhidik asit \%0.2, Oleik asit \%10.4, Linoleik asit \%61.3, Linolenik asit \%4.8. L. edodes'te ise; Palmitik asit \%19.2, Stearik asit \%2.7, Arakhidik asit \%0.4, Oleik asit \%8.3, Linoleik asit \%68.8, Linolenik asit \%0.6 olarak değişkenlik gösterdiği belirtilmiştir. Her iki tür için de oleik ve linoleik asidin toplam yağ oranının \%72-77'si oluşturduğu belirtilmiştir [18].

P. ostreatus şapka yapısında; palmitik asit \%14.0, Stearik asit \%3.0, Oleik asit \%18.0 ve Linoleik asit \%65.0. Misellerinde ise, palmitik asit (\%35.0, Stearik asit \%5.5, Oleik asit \%22.0 ve Linoleik asit \%37.5 [15], A. bisporus ve P. florida türlerinde (\%); kaprik asit 2.38, Lorik asit 0.84, miristik asit 0.25-11.8, palmitik asit 4.2, stearik asit 7.48, oleik asid 12.65-13.91, linoleik asid 35.13, 12.65, 13.91, linolenik asit 35.13, 72.81, araşidonik asit eser düzeyde [17], farklı oranlardaki lokal atıklar üzerinde kültürü yapılan $P$. ostreatus'un yağ asidi $\left(\mathrm{C}_{14: 0}, \mathrm{C}_{15: 0}, \mathrm{C}_{16: 0}, \mathrm{C}_{16: 1}, \mathrm{C}_{17: 0}, \mathrm{C}_{18: 0}, \mathrm{C}_{18: 1}\right.$, $\mathrm{C}_{18: 2,}, \mathrm{C}_{20: 0}$ ) kompozisyonu bakımından ise değişken olduğu belirtilmektedir [17].

A. bisporus ve P. florida türlerindeki yağ asidi kompozisyonu (\%); kaprik asit 2.38, Lorik asit 0.84, miristik asit 0.25-11.8, palmitik asit 4.2, stearik asit 7.48, oleik asid 12.65-13.91, linoleik asid 35.13, 12.65, 13.91, linolenik asit 35.13, 72.81, araşidonik asit eser düzeyde tespit edilmiştir [19].

Pamuk atığı ve pirinç samanından kültüre edilen $P$. florida'nın yağ asidi düzeyleri; miristik asit; \%2.87, palmitik asit; \%3.12-12.3, palmitoleik asit; \%0.50-0.93, oleik asit; \%12.9-13.1, linoleik asit; \%71.2-83.0 değerleri arasında değiştiği ifade edilmektedir [20].

Yapılan bir çalışmada P. sajor-caju'nun yă̆ asidi kompozisyonu incelendiğinde; linoleik, palmitoleik, tetradesenoik asit tespit edilemezken, \%0.6 tetra dekonoik asit, $\% 1.5$ pentadekonoik asit, \%13.9 palmitik asit, \%3.4 stearik asit, \%0.6 eikosanoik asit, \%1.3 dokosanoik asit, \%1.9 tetrakosanoik asit, \%53.8 linoleik asit tespit edilmiştir [21]. Veriler arasındaki değişkenliğin mantarın yetiştirildiği kültür ortamına bağlı olarak ortaya çıktığı düşünülmektedir.

P. ostreatus, $P$. sajor-caju ve $P$. florida'nın yağ asidi çeşitleri ile miktarları; mantar türlerine, yetişme ve farklı kültür ortamına bağlı olarak değişebilmektedir. 


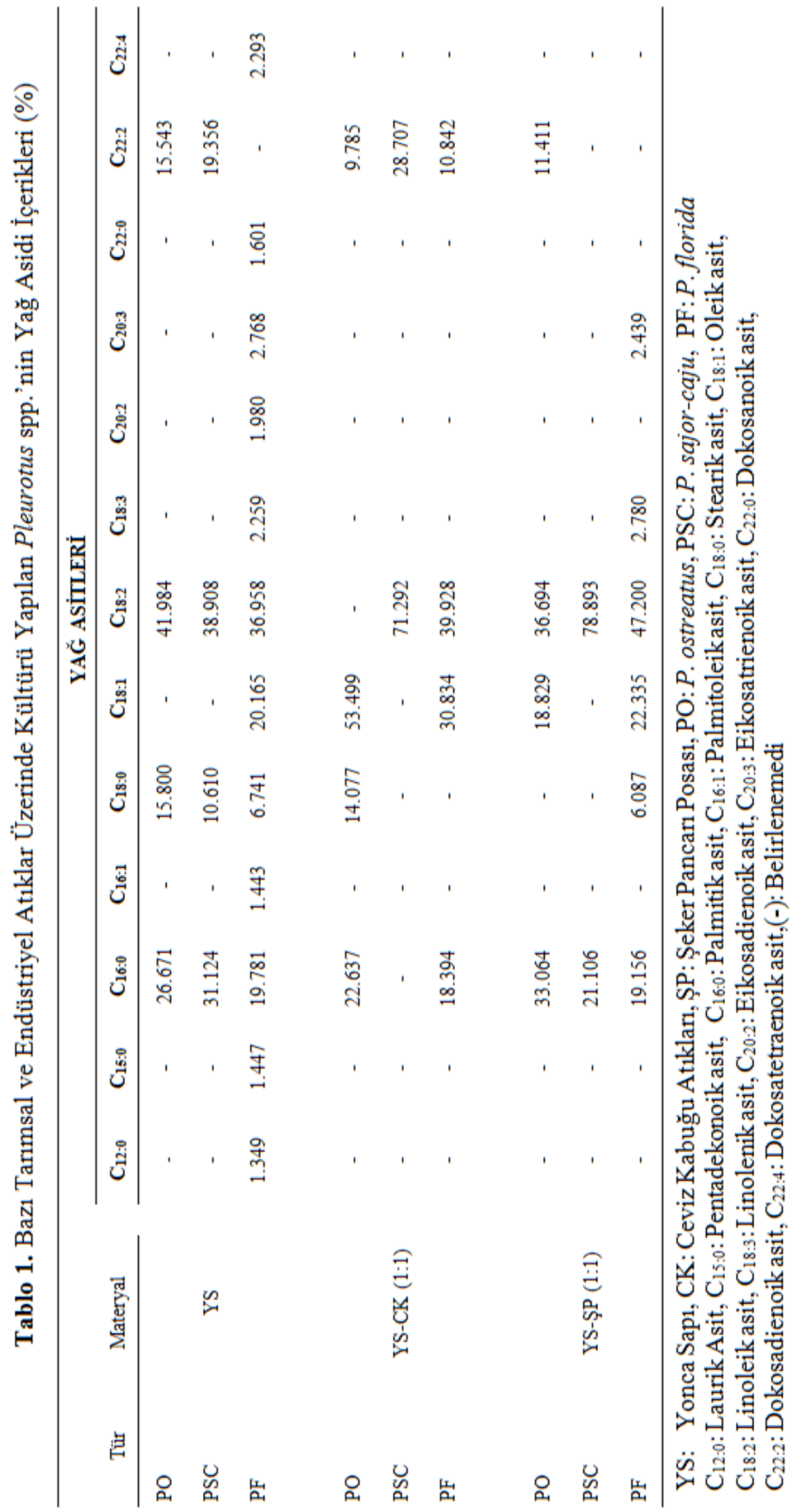




\section{Teşekkür}

Bu çalışma; Fırat Üniversitesi Bilimsel Araştırma Projeleri Birimi (FÜBAP, Proje No:1679) tarafından desteklenmiştir. HPLC analizlerinde katkılarından dolayı Prof. Dr. Ökkeş YILMAZ' a teşekkür ederiz.

\section{Kaynaklar}

1. Jonathan S.G., Fasidi I.O. 2003. Studies on Psathyeralla atroumbonata (Pegler), a Nigerian edible fungus. Food Chemistry, 81: 481-484.

2. Falandysz J, Gucia M. 2008. Bioconcentration factors of mercury by Parasol Mushroom (Macrolepiotaprocera). Environ. Geochem. Health, 30: 121-125.

3. Agrahar-Murugkar D., Subbulakshmi G. 2005. Nutritional value of edible wild mushrooms collected from the Khasihills of Meghalaya. Food Chemistry, 89: 599-603.

4. Jayakumar T., Thomas P.A., Geraldine P. 2009. In-vitro antioxidant activities of an ethanolic extract of the oyster mushroom Pleurotus ostreatus. Innovative Food Science and Emerging Technologies, 10: 228-234.

5. Gyorfi J., Hajdu C.S. 2007. Casing-material experiments with P. eryngii. International Journal of Horticultural Science, 13 (2): 33-36.

6. Kapoor M., Fodhi H.S., Dhandaa S. 1996. Strategies for Strain İmprovement in Pleurotus Species. Mushroom Research, 5: 56-57.

7. Jwanny E.W., Rashad M.M., Abdu H.M. 1995. Solid-state Fermentation of Agricultural Wastes into Food Through Pleurotus cultivation. Applied Biochemistry and Biotechnology, 50,:71-78.

8. Patrabansh S., Madan M. 1997. Studies on Cultivation, Biological Efficiency and Chemical Analysis of Pleurotus sajor-caju ( FR.) Singer on Different Bio-wastes. Acta Biotechnology, 17: 107-122.

9. Gregori C, Schüller C, Roetzer A, Schwarzmüller T, Ammerer G, Kuchler K. 2007. The HighOsmolarity Glycerol Response Pathway in the Human Fungal Pathogen Candida glabrata Strain ATCC 2001 Lacks a Signaling Branch That Operates in Baker's Yeast. Eukaryot Cell, 6 (9):163545.

10. Murcia A.M., Martinez-Tome M., Jimenez A.M., Vera A.M., Honrubia M., Parras P. 2002. Antioxidant activity of edible fungi (truffles and mushrooms): Losses during industrial processing. Journal of Food Protection, 65: 1614-1622.

11. Mattila P., Vaananen P.S., Kongo K., Aro H., Jalava T. 2002. Basic composition and amino acid contents of mushrooms cultivated in Finland. Journal of Agricultural and Food Chemistry, 50: 6419-6422.

12. Adebayo E.A., Oloke J.K., Azeez M.A., Omomowo I.O., Bora T.C. 2014. Assessment of the genetic diversity among ten genotypes of Pleurotus (oyster mushroom) using nutrient and mineral compositions. Scientia Horticulturae, 166: 59-64.

13. Kırbağ S., Korkmaz V. 2013. Sellülozik Atıkların Pleurotus spp.'nin Gelişim Periyodu ve Verimi Üzerine Etkileri. Artvin Çoruh Üniversitesi Orman Fakültesi Dergisi, 14 (2): 239-244.

14. Folch J., Lees M., Sladane-Stanley G.H. 1957. As imple method for the isolation and purification of total lipids from animal tissues. J. Biol. Chem., 226: 497-509.

15. Keser S, Yılmaz Ö, Tuzcu M, Erman O., Irtegun S. 2012. The Effects of Catechin, Lipoic Acid, Resveratrol and Potassium Bromate on Fatty Acid, Lipophylic Vitamins and Cholesterol Levels in Muscle of Wistar Rats. J Chem. Soc. Pakistan, 34 (1) :89-93.

16. Hadar Y, Cohen-Arazi E. 1986. Chemical composition of the edible mushroom Pleurotus ostreatus produced by fermentation. Appl Environ Microbiol, 51: 1352-1354. 
17. Rashad M.M., Abdou H.M. 2002. Production and evaluation of Pleurotus ostreatus mushroom cultivated on some food processing wastes. Advances in Food Sciences, 24 (2): 79-84.

18. Longvah T., Deosthale Y.G. 1998. Compostional and nutritional studies on edible wild mushroom from northeast İndia. Food Chemistry, 63 (3): 331-334.

19. Garcha H.S., Khanna P.K., Son G.L. 1993. Nutritional İmportance of milk, İn Mushroom Biology and Mushroom Products, (S.T., Chang, J.A., Buswell, S.W., Chiu, eds), Chineese University Press. Hong Kong, 227-235 pp.

20. Shashirekha M.N., Rajarathnam S., Bano Z. 2005. Effects of supplementing rice straw growth substrate with cotton seeds on the analytical caharactersitics of the mushroom Pleurotus florida (Block\&Tsao). Food Chiemstry, 92: 255-259.

21. Kavishree S., Hemavathy J., . Lokesh B.R, Shashirekha M.N., Rajarathnam S. 2008. Fat and fatty acids of Indian edible mushrooms. Food Chemistry, 106 (2): 597-602.

Geliş Tarihi: 15.12.2014

Kabul Tarihi: 29.12.2014 